\title{
O PROFESSOR LEIGO QUE ENSINAVA MATEMÁTICA NO SUL DO MATO GROSSO (DÉCADA DE 60 DO SÉCULO XX): história da sUa formação
}

\author{
Alessandra Cristina Furtado ${ }^{1}$ \\ Edvonete Souza de Alencar² \\ Rômulo Pinheiro de Amorim³
}

\section{RESUMO}

Este artigo analisa a história da formação dos professores que ensinavam Matemática, de $1^{a}$ a $4^{a}$ séries, em escolas situadas no meio rural no Sul de Mato Grosso, no município de Dourados, na década de 1960. Para tanto, focalizamos a formação de uma professora leiga que fez o Curso de Regentes, no Centro de Treinamento do Magistério de Cuiabá, no ano de 1969. O trabalho foi realizado por meio de pesquisa documental, tomando dois Cadernos, ligados ao ensino da Matemática da professora investigada, bem como, de outros documentos. Além disso, foi necessário recorrer aos referenciais da história, história da educação, história da educação matemática. Os resultados apontaram que a formação de professores, recebida nesse Centro de Treinamento do Magistério de Cuiabá, era dada no passo a passo, no sentido do como fazer, sendo um curso de rápida formação docente. Contudo, a formação dada no ensino da Matemática era influenciada pelo Movimento da Matemática Moderna. Conclui-se assim, que esse movimento influenciou a história da formação dos professores primários leigos que ensinavam Matemática, que frequentaram os cursos oferecidos pelo Centro de Treinamento do Magistério de Cuiabá.

Palavras-chave: Formação de Professores Leigos. Ensino de Matemática. Movimento da Matemática Moderna.

\footnotetext{
1 Doutora e pós-doutora em Educação pela USP. Professora Associada da Faculdade de Educação na Universidade Federal da Grande Dourados Professora Permanente do programa de pós-graduação em Educação - UFGD. E-mail: alessandra_furtad@yahoo.com.br

2 Doutora em Educação Matemática pela PUC-SP. Professora Adjunta da Faculdade de Educação na Universidade Federal da Grande Dourados. Professora colaboradora no Mestrado profissional Educação Cientifica e Matemática. E-mail: edvonete.s.alencar@hotmail.com

3 Doutorando em Educação da Universidade Federal da Grande Dourados - UFGD. Professor de história da Secretária Estadual da Educação de Mato Grosso. E-mail: romulo79@gmail.com
} 


\title{
LAY TEACHERS WHO TAUGHT MATHEMATICS IN SOUTHERN MATO GROSSO IN THE 1960'S: THE HISTORY OF THEIR EDUCATION
}

\begin{abstract}
This article analyzes the history of the education of teachers who taught Mathematics grade 1 to through grade 4 students in schools located in rural areas in Southern Mato Grosso in the municipality of Dourados in the 1960's. For this purpose, we focused on the education of a lay teacher who completed the Regents Course at the Teacher Training Center of Cuiabá (TTCC), in the year of 1969. The work was done through documentary research, based two notebooks on the teaching of Mathematics by the participant of the study, and other documents. In addition, references from history, history of education and history of mathematics education were also used. The results showed that teachers taking mathematics courses at the TTCC received a "step-by-step" and a "how-to-do" training due to the "fast-track" nature of the courses. The study revealed that the history of the education of the mathematics primary teachers who took the courses offered by the TTCC was influenced by the Modern Mathematics Movement.
\end{abstract}

Keywords: Lay Teacher Education. Mathematics Teaching. Movement of Modern Mathematics.

\section{EL PROFESOR LEIGO QUE ENSEÑABA MATEMÁTICA EN EL SUR DE MATO GROSSO (DÉCADA DEL 60 EN EL SIGLO XX): historia de su formación}

\section{RESUMEN}

Este artículo analiza la historia de la formación de los profesores que enseñaban Matemáticas, de $1^{a}$ a $4^{a}$ grado, en escuelas situadas en el medio rural en el sur de Mato Grosso en el municipio de Dourados, durante la década de 1960. Para ello, enfocamos la formación de una profesora laica que hizo el Curso de Regentes en el Centro de Entrenamiento del Magisterio de Cuiabá, en el año 1969. El trabajo fue realizado por medio de investigación documental, tomando dos Cuadernos ligados a la enseñanza de la Matemática de la profesora investigada, así como de otros documentos. Además, fue necesario recurrir a los referenciales de la historia, historia de la educación, historia de la educación matemática. Los resultados apuntaron que la formación de profesores recibida en ese Centro de Entrenamiento del Magisterio de Cuiabá era dada en el paso a paso, en el sentido de cómo hacerlo, siendo un curso de rápida formación docente. Sin embargo, la formación dada en la enseñanza de las Matemáticas era influenciada por el Movimiento de la Matemática Moderna. Se concluye así que ese movimiento influenció la historia de la formación de los profesores primarios laicos que enseñaban Matemáticas, que frecuentaron los cursos ofrecidos por el Centro de Entrenamiento del Magisterio de Cuiabá.

Palabras clave: Formación de Profesores Laicos. Enseñanza de Matemáticas. Movimiento de la Matemática Moderna. 


\section{INTRODUÇÃO}

Todo dia o sol levanta

E a gente canta

Ao sol de todo dia [...] Madrugada, um céu de estrelas

E a gente dorme Sonhando com o dia Música:Canto de Um Povo de Um Lugar (VELOSO, 1975)

A nossa abordagem neste artigo inicia-se com a música "Canto de Um Povo de Um Lugar", de autoria de Caetano Veloso e interpretada por diversos cantores brasileiros. Essa música com os seus versos simplistas que relacionam com momentos do cotidiano e demonstram a vida do povo do campo e do sertanejo, retratando um público de origem humilde e nem sempre estudado, mas com grandes conhecimentos sobre a vida e o trabalho. No entanto, um povo que vive do trabalho diário, de sol a sol e sonha com um novo dia. Assim, o artigo aqui proposto, emerge de um cenário bem semelhante a esse, visando contemplar a temática deste dossiê sobre a "história da formação do professor que ensina Matemática".

Este artigo busca analisar a história da formação dos professores que ensinavam Matemática, de $1^{a}$ a $4^{a}$ séries, em escolas situadas no meio rural no Sul de Mato Grosso, no município de Dourados, na década de 1960. Especificamente, neste artigo, focalizaremos a formação de uma professora leiga que fez o Curso de Regentes no Centro de Treinamento do Magistério de Cuiabá, no ano de 1969. O recorte temporal na década de 1960 justificase por abranger o período de atuação profissional da professora leiga pesquisada, em escolas primárias, situadas no município de Dourados e de sua formação no Centro de Treinamento do Magistério em Cuiabá.

Para desenvolver este trabalho, além dos cadernos da professora leiga e aluna do Curso de Regentes do Ensino Primário, do Centro de Treinamento do Magistério de Cuiabá, foi necessário recorrer também a documentos como as Mensagens de Governadores de Mato Grosso, e outros. Utilizamos, ainda, as referências ligadas à História, à História da Educação, à História da Educação Matemática. 
Os cadernos aqui pesquisados foram localizados no arquivo pessoal da professora leiga, que guarda e preserva até os dias de hoje, com muito zelo e dedicação os materiais que foram utilizados em sua formação docente, no Centro de Treinamento do Magistério de Cuiabá. Assim, este trabalho tem como questões norteadoras, indagar: Como ocorria a formação dos professores leigos primários, para ensinar a Matemática, no Centro de Treinamento do Magistério de Cuiabá? De que maneira estava representado, nos cadernos pesquisados, o ensino da Matemática recebido por esses professores leigos?

O artigo foi organizado em quatro partes. A primeira e a segunda versaram sobre a história da formação dos professores primários no Sul de Mato Grosso e no Centro de Treinamento do Magistério de Cuiabá. A terceira apresenta o Movimento da Matemática Moderna e, por fim, a última parte, aborda a análise dos cadernos selecionados para a pesquisa.

\section{A história da formação do professor primário no Sul de Mato Grosso}

No sul de Mato Grosso, a história da formação de professores primários é marcada pela instalação tardia de Escolas Normais, condições precárias de funcionamento, falta de professores diplomados, para atuar no ensino primário, sobretudo, nas escolas rurais.

É oportuno destacar, que foi apenas vinte anos após a instalação da primeira Escola Normal, em Cuiabá, que ocorreu a criação de outra instituição da mesma natureza, no Estado. Desta vez, a Escola Normal foi instalada em Campo Grande, em 21 de abril de 1930, anexa ao Grupo Escolar, pelo então presidente de Estado, Dr. Aníbal Toledo, tornando-se a primeira instituição sul-mato-grossense dessa natureza e a segunda do Estado.

Embora não bastasse a espera para a instalação de outra instituição formadora de professores primários em Mato Grosso, a Escola Normal de Campo Grande, dez anos após a sua instalação, mais precisamente em 1940, foi fechada. Esse fechamento ocorreu em consequência da reforma que o governo de Júlio Strübing Müler (1937-1945) tentou implantar. Com 
essa reforma, a referida Escola permaneceu fechada por sete anos e a Seção Normal, que era a antiga Escola Normal, e o Curso Especializado de professores, funcionaram nos três ginásios oficiais com que contava o Estado, situados nas cidades de Cuiabá, Corumbá e Campo Grande.

A Escola Normal de Campo Grande foi restituída oficialmente, por meio do Decreto-Lei no. 834, de 31 de janeiro de 1947, somente no governo de José Marcelo Moreira (1946-1947), que a organizou em dois ciclos, de acordo com as prescrições estabelecidas pela Lei Orgânica do Ensino Normal de 1946:

Art.1- Fica o Poder Executivo autorizado a criar, nos termos do decreto-lei n. 8530, de 2 de janeiro de 1946, duas Escolas Normais na Capital do Estado e em Campo Grande, com as designações respectivamente de, Escolas Normal "PEDRO CELESTINO" e "JOAQUIM MURTINHO".

Art. 2 -, que serão dirigidas respectivamente por diretor padrão $M$, em comissão e diretamente subordinado ao Departamento de Educação e Cultura do Estado, destinam-se a prover a formação do pessoal docente necessário ás escolas primárias do Estado.

Art. 3 - As Escolas Normais "PEDRO CELESTINO" e "JOAQUIM MURTINHO" de conformidade, com a Lei Orgânica do Ensino Normal no país, ministrarão o ensino em dois ciclos. O primeiro dará o curso de regentes do ensino primário, em quatro (4) anos, e o segundo o curso de formação de professores primários, em três (3) anos ${ }^{4}$.

No governo de José Marcelo Moreira também foi elaborado o Regulamento das Escolas Normais do Estado, promulgado pelo Decreto no. 287, de 26 de março de 1947, que determinava:

Art. 1 - o ensino normal tem por fim:

- Promover a formação do pessoal necessário ás Escolas primárias do Estado.

- Habilitar administradores escolares destinados às mesmas escolas.

- Desenvolver e propagar os conhecimentos e técnicas relativas à educação da infância.

Art. 2 - O ensino ministrado pelas Escolas Normais do Estado será gratuito e facultado a ambos os sexos 5 .

\footnotetext{
4 Fonte: Mato Grosso. Governo do Estado (1947). Decreto-Lei no. 834, de 31 de janeiro de 1947. Diário Oficial, Cuiabá, 4 de fevereiro de 1947, ANO LVI, p. 9867. Arquivo Histórico de Mato Grosso/ Centro de Documentação Regional da Universidade Federal da Grande Dourados.

5 Fonte: Mato Grosso. Governo do Estado (1947). Decreto-Lei n. 287, de 26 de março de 1947. Diário Oficial, Cuiabá, 31 de março de 1947, ANO LVI. Arquivo Histórico de Mato Grosso/ Centro de Documentação Regional da Universidade Federal da Grande Dourados.
} 
Com a reabertura da Escola Normal em Campo Grande e a elaboração do Regulamento das Escolas Normais em Mato Grosso, que o Ensino Normal no Estado conheceu um processo de reabilitação e propagação. No entendimento de Marcílio (1963), foi a partir desse processo, que se implantaram ações políticas, concedendo ao setor privado, O Ensino Normal e delegando a formação de professores, principalmente, ao setor confessional, que desencadearam a instalação, no sul de Mato Grosso, da Escola Normal, anexa ao Ginásio Maria Auxiliadora, pertencente à Congregação das Filhas de Maria Auxiliadora, ala feminina da Ordem Salesiana, em Campo Grande, e outra Escola Normal privada, também mantida pelas Irmãs Salesianas, em Corumbá. E, em 1949, a criação da Escola Normal de Aquidauana, mediante a Lei n. 342.

Mesmo com esse processo de reabilitação e expansão do Ensino Normal, desencadeado no governo de José Marcelo Moreira, a Escola Normal de Campo Grande, a segunda instituição oficial do estado de Mato Grosso, ainda permaneceu funcionando em condições precárias, até o final da década de 1960 e início de 1970. Nessas circunstâncias, a parte Sul do estado sofria com a falta de professores diplomados na Escola Normal, para atuar nas escolas primárias, sobretudo, nos estabelecimentos escolares situados no meio rural. A Mensagem enviada à Assembléia Legislativa no ano de 1952, pelo governador Fernando Corrêa da Costa, ilustra bem essa situação em Mato Grosso, ao registrar a condição dos professores que atuavam nas áreas rurais do Estado:

(...) Somos forçados a reconhecer que o ensino em Mato Grosso está sofrendo uma perigosa involução, um ressaltante retrocesso. É verdade que para as escolas das cidades especialmente das que oferecem melhores condições de conforto e de progresso, ainda se obtém professora, o que não se registra quando se trata de preenchimento das unidades rurais. Diante dessa contingência, as mais das vezes, vemos guindados à posição de professor criaturas semi-analfabetas ${ }^{6}$.

${ }^{6}$ Fonte: Idem. 
Embora a formação de professores das áreas rurais fosse um problema enfrentado por todo o estado de Mato Grosso, as Mensagens de Governadores (1930-1960) permitiram entrever que essa situação era mais agravante na parte Sul, "onde os docentes leigos assumiam, principalmente, as classes de $1^{a}$ série". (MENSAGEM DE GOVERNADOR DE MATO GROSSO, 1936, p.26). Convém esclarecer aqui, que os professores leigos, eram considerados como docentes que não tinham conhecimentos e capacidade profissional necessária, para lecionarem nas escolas do Estado. Essa categoria de professores era marginalizada e inferiorizada no campo educacional de Mato Grosso, na perspectiva do governo estadual.

Essa autarquia considerava a atuação no magistério, exercida por professores leigos, como um dos grandes problemas que prejudicavam a melhoria do ensino público em Mato Grosso. Entretanto, a existência de um número elevado de docentes sem habilitação, exercendo a docência nas escolas primárias do Estado, pode ser compreendida pela falta de uma quantidade de escolas necessárias para a formação de professores.

Apesar do aumento do número de Escolas Normais criadas no Estado após os anos 1930, como foi o caso da Escola Normal em Campo Grande e das outras que também foram instaladas no Sul, pertencentes à iniciativa privada, em Campo Grande, Corumbá e Aquidauana, a demanda por professores normalistas era muito maior, pois o aumento populacional e expansão das escolas primárias contribuíram para esse fato. Diante desta situação, as escolas primárias, principalmente, as localizadas na zona rural, atendiam a escolarização dos alunos com a inserção de professores leigos nas instituições escolares. Esses docentes eram oriundos, geralmente, das próprias comunidades onde residiam.

Contudo, foi essa falta de professores diplomados para atuar nas escolas primárias de Mato Grosso, principalmente, nas áreas rurais, que levaram o governo estadual, em parceria com o governo federal, a adotar e implantar políticas para habilitação dos professores leigos, nos anos de 1960 , em nível pedagógico, por meio de metodologia de ensino direto, no período 
de férias, e indireto, oferecido em período letivo, com a criação do Centro de Treinamento do Magistério de Cuiabá.

\section{- Centro de Treinamento do Magistério de Cuiabá e os novos redirecionamentos para a história da formação de professores}

O Centro de Treinamento do Magistério de Cuiabá, foi criado no contexto da Reforma do Ensino Primário, promovida pelo Governo João Goulart, no período de 1963 a 1964. O Plano Trienal de Educação, de João Goulart,

além de estabelecer objetivos para o ensino primário, médio e superior, previa os recursos financeiros e a assistência técnica necessária à implantação de programas de construções de prédios escolares e de recuperação e aperfeiçoamento do magistério (BRASIL, 1963).

O Plano Trienal de Educação de João Goulart pretendia instituir, nada menos do que, 40 Centros de Treinamento do Magistério, nos próximos 8 anos, e, talvez, para os próximos 3 anos, pelo menos 18 destes centros em diferentes localidades do Brasil (FERREIRA, 2010). Nesse contexto, o Programa de Aperfeiçoamento do Magistério Primário (PAMP) foi criado em 1963, pelo governo federal, com o objetivo de subsidiar os cursos já mencionados, voltados para a habilitação de professores leigos. A partir deste Programa, os recursos se multiplicaram (RODRIGUES, 1985).

O interesse no aperfeiçoamento de professores leigos, por meio de cursos de treinamento idealizado pelo INEP, foi incorporado no Plano Trienal de Educação no início dos anos 1960, assim como, a articulação do governo brasileiro com a assistência técnica e financeira, advinda dos acordos com os EUA, que resultaram na implantação do PABAEE (Programa de Assistência Brasileiro-Americana ao Ensino Elementar) no país. Esse programa exerceu influência pedagógica, no aprimoramento dos professores leigos de diversas regiões do Brasil, como foi o caso de Mato Grosso, com o fornecimento da literatura produzida pelo programa como subsídio para o treinamento de professores leigos no estado. 
Em Mato Grosso, a instalação do Centro de Treinamento do Magistério de Cuiabá, fez-se em um período de extrema necessidade e urgência para o Estado. A esse respeito, o ex-secretário estadual de Educação e Saúde do Mato Grosso, Humberto Marcílio, anunciava que "em 1963, mais de $60 \%$ dos professores primários que atuavam no Estado não tinham formação adequada" (MARCílIO, 1963, p. 214). Hermes Rodrigues de Alcântara, titular da pasta de Educação e Saúde de Mato Grosso, em 1963, também manifestava a sua preocupação com a questão.

Ao iniciarmos a nossa gestão, um dos problemas que nos desafiava, relativamente ao Ensino, era o grande número de professores leigos, efetivados por concurso. [...] O trato diário com os problemas educacionais evidenciou, desde cedo, a necessidade da recuperação daqueles professores que, embora efetivados, não possuem, contudo, um grau suficiente de conhecimentos e de capacidade profissional (MARCílIO, 1963, p. 215).

No Centro de Treinamento do Magistério de Cuiabá eram oferecidos cursos de especialização em supervisão escolar, para professoras normalistas e cursos de aperfeiçoamento, para professoras qualificadas como "leigas" (FERREIRA, 2010). A autora, ainda, ressalta:

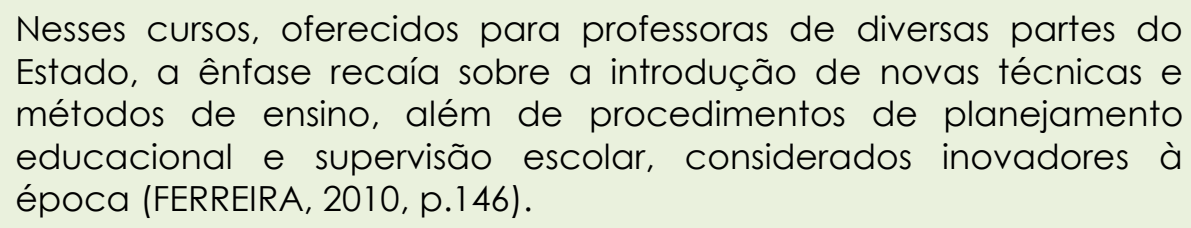

Entretanto, no início de seu funcionamento, o Centro deparou-se com a dificuldade de contratação de pessoal habilitado. No entanto, para resolver essa situação, foram convocados docentes para realizar

Cursos de especialização em matérias do currículo primário e de especialização em supervisão, oferecidos pelo Centro de Treinamento de Belo Horizonte, que funcionava junto ao PABAEE7 (Programa de Assistência Brasileiro-Americana ao Ensino Elementar) (PINHO, 1964, p. 6).

O PABAEE ficou conhecido por contribuir para consolidar, no campo educacional brasileiro nos anos de 1960, a perspectiva tecnicista na análise 
das questões educacionais. Ao todo, portanto, quase 90 professoras matogrossenses iniciaram, em 1963, cursos de especialização promovidos pelo "Programa de Recuperação e Aperfeiçoamento do Magistério", do governo Goulart (PINHO, 1964).

Mesmo com a saída de João Goulart, em virtude do Golpe Militar de 1964, o Centro de Treinamento do Magistério de Cuaibá manteve o seu funcionamento, respeitando as determinações dos dispositivos relativos à educação, presentes no Programa de Ação Econômica do Governo (PAEG), elaborado sob a coordenação do economista Roberto Campos.

Contudo, a partir deste período de 1964, esse Centro passou a concentrar-se mais, nas atividades de oferta de cursos de férias a professoras "leigas" e cursos de difusão de novos métodos pedagógicos. Os cursos de férias eram intensivos de aperfeiçoamento do professorado leigo, realizados em Cuiabá. Já os cursos de difusão de novos métodos pedagógicos, com duração de 15 dias, eram oferecidos por uma equipe de professoras especialistas, para docentes de Escolas Normais, Ginásios e Escolas Primárias públicas e privadas, em seus municípios de origem (FERREIRA, 2010).

O oferecimento de cursos de formação e aperfeiçoamento de professores em cursos intensivos pode revelar a estratégia governamental de ampliar o número de professores capacitados, diante de uma grande quantidade de professores leigos no magistério e da falta de atualização pedagógica dos professores normalistas. Entretanto, a capacitação de professores em curto prazo, não era a única estratégia governamental na educação, a organização do currículo e dos saberes escolares a serem adquiridos pelos professores, era uma das maneiras para introduzirem as modificações nas práticas pedagógicas docentes, com o intuito de oferecerem profissionais mais eficientes para atuarem na aprendizagem dos alunos.

No Curso de Regentes de Ensino, por exemplo, no final da década de 1960, o currículo estava organizado em áreas de estudos, conforme pode se observar: 
Quadro 1: Áreas de estudos do Curso de Regentes de Ensino

- Português

- Psicologia Educacional

- Currículo e Supervisão

- Aritmética

- Metodologias: Estudos Sociais - Ciências- Aritmética -Linguagem

- Didática do Pré-Primário

- Artes Aplicadas

- Pedagogia da Escola Unitária

- Geografia

- História

- Recreação e Jogos.

Fonte: Certificado de Conclusão do Curso de Regentes do Ensino Primário do Centro de Treinamento do Magistério de Cuiabá de 1969

O quadro permite entrever as matérias ministradas no Curso de Regentes de Ensino em 1969. A estrutura curricular do curso direcionava para a formação de professores com base no aprendizado de conhecimentos $e$ técnicas necessárias para propiciar ao professor à capacidade de alfabetizar os alunos, bem como apreender instrumentos educacionais para desenvolver as habilidades de ler, escrever e calcular.

Deste modo, o currículo direcionava a formação de professores com base no aprimoramento na capacidade de instruir os alunos, no sentido de subsidiar os professores, com técnicas de ensino, capazes de proporcionar o aprendizado de maneira prática, fazendo com que os alunos aprendessem conteúdos, por meio da participação nas técnicas de ensino, coordenadas pelos professores nas aulas. O fundamental para os professores era saber como ensinar, para que isso se consolidasse em seu perfil profissional, de maneira a ter ferramentas pedagógicas para ensinar os conhecimentos científicos aos alunos.

Apesar da participação dos professores e alunos em uma interação maior no processo de aprendizagem, o objetivo é a racionalização dos meios, pois a centralidade está associada no como fazer, nos meios para fazer. Nessa situação, os professores e alunos ocupam posição secundária, porque 
são apenas executores dos meios pré-estabelecidos pelos especialistas em educação, como poderá ser observado nas análises dos cadernos no último subitem deste artigo.

Os professores que estavam no processo de aprimoramento pedagógico no curso, foram envolvidos em um currículo que procurava instrumentalizar os professores cursistas de conhecimentos sobre 0 funcionamento emocional, intelectual e físico das crianças, como forma de conhecer melhor as crianças/alunos, as suas formas de comportar, de agir e de aprender.

A criação do Centro de Treinamento do Magistério de Cuiabá, no ano de 1963 possibilitou a realização do aperfeiçoamento pedagógico dos professores leigos e normalistas do estado, com o oferecimento de cursos de atualização de conhecimentos educacionais a diversos docentes. Esta instituição escolar foi responsável pela reformulação dos métodos de ensino, pois o governo já havia mencionado o atraso pedagógico que estava vivenciando as Escolas Normais do estado, bem com, pelo problema da atuação de professores leigos no magistério primário, já que, esta categoria de docentes, era considerada pelo governo como inadequada, para exercerem as atividades de ensino, por não possuírem os conhecimentos necessários para lecionarem nas escolas primárias do Estado.

A especialização em educação ofertada no Centro de Treinamento do Magistério de Cuiabá, por meio dos cursos de Supervisão do Ensino Primário, de Administração para diretores de escolas e o Curso de Treinamento de Professores Leigos, evidencia as intenções do governo estadual em aprimorar os conhecimentos pedagógicos dos professores, com a finalidade de melhorar o nível de atuação profissional dos docentes. A criação de instituições escolares indicam o papel do Estado no direcionamento da reprodução das normas e saberes aos professores (NÓVOA, 1995).

Deste modo, o centro foi destinado para que os especialistas em educação, formados pelo próprio centro e os especialistas que retornaram para Mato Grosso, após os cursos realizados em Minas Gerais, São Paulo e 
Rio de Janeiro, desenvolvessem o trabalho de difusão dos novos conhecimentos pedagógicos, por meio de cursos intensivos aos professores mato-grossenses.

É nesse quadro constituído, tanto pelas escolas normais, quanto pela atuação do Centro de Treinamento de Cuiabá, que ocorria a formação dos professores primários em Mato Grosso, ainda no início dos anos de 1970, mas que ainda não era suficiente para atender a toda à demanda de professores que atuavam sem diploma nas escolas primárias, sobretudo nas do meio rural. Com vistas, ao período de abragência deste artigo, que busca analisar a história da formação do professor que ensinava Matemática de $1^{a}$ a $4^{a}$ série, será necessário uma abordagem nesse contexto sobre o Movimento da Matemática Moderna para verificar suas influências.

\section{Movimento da Matemática Moderna - MMM}

No Brasil, na década de 1960 iniciou-se um movimento internacional chamado Movimento da Matemática Moderna - MMM. Os Parâmetros Curriculares Nacionais de Matemática - PCNM indicam que, nesse período histórico (60/70), do século XX, o Brasil foi influenciado por estudos de diversos países que traziam discussões sobre a modernização do ensino de Matemática, que viabilizasse o desenvolvimento do pensamento critico e tecnológico. E, para que isso acontecesse, era necessária uma reforma pedagógica. Assim, nesse período:

a Matemática a ser ensinada era aquela concebida como lógica, compreendida a partir das estruturas, conferia um papel fundamental à linguagem matemática. Os formuladores dos currículos dessa época insistiam na necessidade de uma reforma pedagógica, incluindo a pesquisa de materiais novos e métodos de ensino renovados - fato que desencadeou a preocupação com a Didática da Matemática, intensificando a pesquisa nessa área (BRASII, 1998,p19).

Com o fato de que mudanças eram necessárias para que o MMM ocorresse, intensificou-se a criação de grupos de estudo no país. Wielewski (2008) fez um levantamento sobre a formação de grupos de professores no 
Brasil e a influência do MMM. Em seu estudo, a autora relata que este movimento foi um projeto de internacionalização, no qual, as ideias da comissão internacional para analisar o ensino de Matemática, comissão esta, criada em 1908, serviram de referência para a criação do movimento quase 50 anos depois.

Valente (2012) menciona que as primeiras ideias sobre o que o autor denomina de "revolução estruturalista" 8 , começam a surgir, no período entre guerras com os membros do Círculo de Praga com Roman Jakobson. O autor nos diz que o termo estrutura, começa a ser utilizado em 1929. Posteriomente, em seis anos, um grupo é formado por pesquisadores matemáticos, especificamente também por Bourbaki que se apropria da utilização da estrutura. Cita, ainda que, nessa época houve influência de alguns pesquisadores da psicologia como, por exemplo, Piaget que começa a se interessar por Matemática e utiliza os conhecimentos de Bourboki. Este período foi marcado por diversos eventos da área da Matemática e da Psicologia, para discutirem sobre o uso da estrutura para o ensino de Matemática. Esses eventos proporcionaram um incentivo europeu para que houvesse a formação e divulgação da transformação da Matemática escolar. Valente (2012) refere-se ainda que:

Em 1959, a OECE - Organização Europeia de Cooperação Econômica promove um inquérito relativamente ao ensino de matemática em seus países membros. Além do levantamento de informações, a OECE patrocina um encontro para discutir os dados obtidos, com vistas à promoção de uma reforma curricular do ensino de matemática (VALENTE, 2012, p.1428).

Tais influências chegaram até o Brasil, por meio de participação de pesquisadores em eventos internacionais. Com isso, Wielewski (2008) também em seus estudos afirma a influêcnia internacional no país.

Dessarte, no final de 1950 e ínicio de 1960, o MMM era discutido e desenvolvido em vários países do mundo e "pretendia-se aproximar a Matemática trabalhada na escola básica com a Matemática produzida

\footnotetext{
8 A revolução estruturalista refere-se as mudanças para o ensino de Matemática utilizandose de estruturas e abstrações, ocosionadas pelo Movimento da Matemática Moderna.
}

Revista Exitus, Santarém/PA, Vol. 9, №2, p. 105 - 130, ABR/JUN 2018. 
pelos pesquisadores da área" (WIELEWSKI, 2008, p.1). Tal fato, também é evidenciado pelo PCNM mencionando que o ensino deveria ser "centrado nas estruturas e fazendo uso de uma linguagem unificadora" (BRASIL, 1998, p.19). Acreditavam, ainda, que com as mudanças proporcionadas pela MMM preparariam as pessoas para melhor lidar com os desenvolvimentos tecnológicos. Wielewski (2008) aponta ainda que:

as propostas veiculadas pelo MMM inseriram no currículo conteúdos matemáticos que até aquela época não faziam parte do programa escolar como, por exemplo, estruturas algébricas, teoria dos conjuntos, topologia, transformações geométricas (WIELEWSKI, 2008, p.1).

Como esses conteúdos até então, não faziam parte do currículo formativo dos professores, houve incentivo de formações para que a modernização trazida pelo MMM fosse aprendida pelos professores. Essa problemática é abordada por Brasil (1998), pois estes conteúdos estavam fora do alcance do conhecimento dos estudantes, principalmente, das séries iniciais. Havia uma preocupação maior com as abstrações teóricas do que com os aspectos práticos. O documento cita um exemplo que o uso da Teoria dos conjuntos prejudicou consideravelmente o ensino de cálculo, medidas e geometria (BRASII, 1998, p19). Wielewski (2008) complementa que esses professores deveriam com a implementação do MMM aprender um novo roteiro de conteúdo e de metodologias a serem desenvolvidas. Para que isso fosse realizado no Brasil, alguns grupos de estudos e formações foram criados para o incentivo a utilização do MMM.

Wielewski (2008) aponta que os grupos de estudos com os professores de Matemática foram formados de maneira mais organizada nas décadas de 60 e início de 70, do século XX, nas regiões litorâneas. No entanto, a autora menciona um grupo da região Centro-Oeste, no estado do Mato Grosso, que se preocupava com o ensino de Matemática na região. O grupo GEPEMAT (Grupo de Ensino e Pesquisa em Educação Matemática) foi criado em 1985 e identificou que as influências do movimento no estado iniciaram apartir de 1973 e prosseguiram com formações até 1989, tal fato 
explica influência desse movimento em registros nos planejamentos de professores primários rurais nos estudos de Bicudo, Furtado e Alencar (2017).

Assim, além da realização dos grupos de estudos com professores de Matemática, Wielewski (2008) nos indica a existência de dois fatores determinantes para propagação do MMM no Brasil, o primeiro a participação de pesquisadores brasileiros em congressos internacionais e o segundo para a divulgação no país a participação desses pesquisadores em congressos nacionais. Além disso, segundo Brasil (1998), a MMM foi dissiminada também pelos livros didáticos.

No entendimento da autora todas as modificações ocorridas no ensino de Matemática no Brasil e influênciadas pelo MMM, ocorreram em níveis de ensino distintos, há regiões do país que foram implementadas desde os primeiros anos do ensino primário e há regiões que foram desenvolvidas atividades no ensino secundário, algumas regiões em classes experimentais? e outras em sua totalidade.

Wielewski (2008) ainda reforça que essas distinções ocorreram por influência dos grupos de estudos de professores de Matemática, não havendo uma política pública que oficializasse sua organização no país e o incentivo político foi realizado por meio de convênios e projetos para a formação de professores.

Para ilustrar tal influência do Movimento da Matemática Moderna na história da formação do professor primário em Mato Grosso, que ensinava Matemática, analisaremos um Caderno de Didática de Aritmética e outro Caderno de Prática ${ }^{10}$ para o ensino da Matemática, de uma professora leiga do Sul de Mato Grosso, que foi ex-aluna do Curso de Regentes oferecido em 1969, no Centro de Treinamento do Magistério de Cuiabá.

\footnotetext{
9 "as Classes Experimentais Secundárias seguiam o ideal de renovação e inovação destas Escolas e buscavam, através de novas organizações curriculares e práticas pedagógicas, as soluções para o Ensino Secundário Brasileiro" (VIEIRA, DALLABRIDA e STEINDEL, 2013, p.3).

10 Intitulamos este Caderno como de Práticas do ensino da Matemática, pois a aluna não nomeia, mas deixa a entender que era um caderno, em que ela registrava as práticas de Matemática aprendidas no Curso de Regentes do Centro de Treinamento do Magistério de Cuiabá.
} 


\section{Como a professora leiga aprendia para ensinar Matemática}

Ao analisarmos o Certificado de Conclusão da professora leiga e os seus cadernos, identificamos que sua formação deu-se no Curso de Regentes de Ensino Primário, que foi realizado no período de março a novembro de 1969, no Centro de Treinamento do Magistério de Cuiabá, sendo a coordenadora estadual Ana Luiza de Figueiredo e que atesta 0 referido certificado. As áreas de estudo cursadas como já relatadas em item anterior, apresentavam áreas de estudo. Dentro destas áreas de estudo identificamos, as que podem colaborar com nossa investigação sobre a formação desse profissional para o ensino de Matemática são: Aritmética, Metologias: Aritmética e Didática do pré-primário.

Um dos cadernos da professora leiga selecionado para esta análise, é referenciado como Didática da Matemática, porém, inferimos ser da área de Metodologia de Aritmética. No entanto, para essa análise selecionamos somente as abordagens sobre a Teoria dos Conjuntos. Além disso, utilizaremos o caderno de práticas para o ensino de Matemática, que também apresenta atividades sobre a Teoria dos Conjuntos.

O caderno Didática da Matemática iniciou suas atividades em 12 de março de 1969, este realiza uma abordagem geral sobre como seria o início das atividades com os alunos, sugerindo o traballho com o nome se fosse esta a primeira vez, na escola do aluno e ainda aborda sobre a importância de um trabalho inicial para observar questões psicológicas, como identificar características comportamentais como: os alunos mais tímidos desembaraçados, entre outros. Isso nos remete aos estudos de Valente (2012) que menciona sobre a influência da Psicologia no MMM para o ensino, pois este caderno dava também as professoras leigas sugestões sobre o desenvolvimento do raciocínio mental: rápido e lento.

Além dessa influencia do MMM utilizado na formação do professor primário, o caderno apresenta ainda os registros da importância de "iniciar a criança na aquisição de conceitos e vocabulário quantitativo, básico e na formação de significado numérico" (REGISTRO DO CADERNO).

Sugere como atividades para o período inicial: 
"conversas informais, atividades para a formação de quantitativos básicos, conceitos, vocabulários, quantidades : muito e pequeno, alguns mais e menos; tamanho maior, menor, alto e baixo; tempo cedo, tarde, hoje e amanhã; posição em cima embaixo, sob e sobre, esquerda e direita; medida de tempo; ordem: primeiro, ultimo ; sentido, formas geométricas,; valor caro; barato; temperatura: quente, frio; capacidade cheio, vazio; frações" (REGISTRO DO CADERNO).

Todas essas sugestões de atividades tinham como objetivo preparar para o desenvolvimento do sistema de numeração, assim como também para o entendimento das operações fundamentais.

Em outro registro, no dia 28 de março de 1969 retomou-se as formações no desenvolvimento de Didática da Matemática, no qual iniciouse com a temática sobre Teoria dos Conjuntos. Observamos como dados apontados por Brasil (1998) e Wielewski (2008), que a Teoria dos conjuntos não estava presente no currículo brasileiro até a influência do MMM. Conforme esses autores o movimento possibilitou a mudança do ensino de Matemática, tornando-o segundo Valente (2012) mais estruturalista. Assim desvelamos um dado importante, visto que os registros de formação desta professora leiga são de 1969, e evidenciam que neste ano, as formações já sofriam influência do MMM. Tal fato, amplia a descoberta do grupo GEPEMAT, que segundo Wielewski (2008), as formações com essa influência só ocorreram a partir de 1973, em Mato Grosso.

Os registros formativos mostram de forma organizada como a docente deveria iniciar o trabalho com Teoria dos Conjuntos. Para a percepção dos conjuntos era preciso verificar o vocabulário das crianças, estimular a descoberta de diferentes objetos, definir sobre o trabalho com limite dos conjuntos e uso de materiais como flanelógrafo. Essas práticas formativas estimulava a correspondência entre os elementos dos conjuntos. Sugeriam na formação como deveriam iniciar com a equivalência, prevendo quantidade de objetos do conjunto ideal para o trabalho, até como a ligação do numeral a sua quantidade, solicitavam para que os alunos realizassem desenhos observando a quantidade dos números de elementos. 
Além disso, apresentavam cartazes com as informações dos conjuntos estudados. Para o trabalho formativo com os conjuntos não equivalente, a proposta era começar com um conjunto de quatro elementos e outro de três, fazendo sempre perguntas aos estudantes. Os conjuntos deveriam ser aos poucos ampliar a quantidade. Por exemplo, "através de atividades semelhantes o professor levara a criança ao conhecimento do número 5 tendo o cuidado de conduzir a classe a entender o cinco como um a mais que o quatro" (REGISTRO DO CADERNO). Para os demais conjuntos com números maiores se sugeria trabalho semelhante.

Para desenvolver as atividades com os alunos para a comparação dos conjuntos era sugerido o uso do flanelógrafo; atividades de sala de aula que permitissem o desenho na lousa dos conjuntos. E, a partir desses ensinamentos ia-se para o agrupamento dos elementos do conjunto que segundo Registro do Caderno seriam essenciais para a compreensão das operações, conforme figura 1 a seguir:

FIGURA 1: Como se ensina agrupamento de elementos do conjunto


Fonte: Arquivo Pessoal da Professora Leiga. 
Era proposto assim, que se agrupassem com diversos elementos, com o intuito de desenvolver o conceito de número. É importante destacar aqui que Piaget construiu provas matemáticas e as estruturas necessárias de identificação para o conceito do número, o que nos leva a relacionar as considerações de Valente (2012). A esse respeito, os Registros dos Cadernos sugerem ainda que o conhecimento do agrupamento dos elementos auxiliará nas operações fundamentais de adição e subtração, ao unir um conjunto ou separar um conjunto, como podemos observar nas imagens dos cadernos, conforme figura 1 , que registra a formação dando o direcionamento de atividades que poderiam ser realizadas com os estudantes. Inferimos que tal direcionamento era dado desse modo, para facilitar o pouco tempo hábil para a realização do curso de formação. Além disso, não conseguimos identificar indícios sobre o real entendimento dos docentes sobre o assunto. Consideramos que as informações passadas desse modo, tornavam-se rasas, visto a complexidade e necessidade que a formação necessitaria.

Encontramos nos Registros dos Cadernos também as orientações para o desenvolvimetno da escrita dos numerais, conforme figura 2.

FIGURA 2: Orientações para o desenvolvimento da escrita dos números

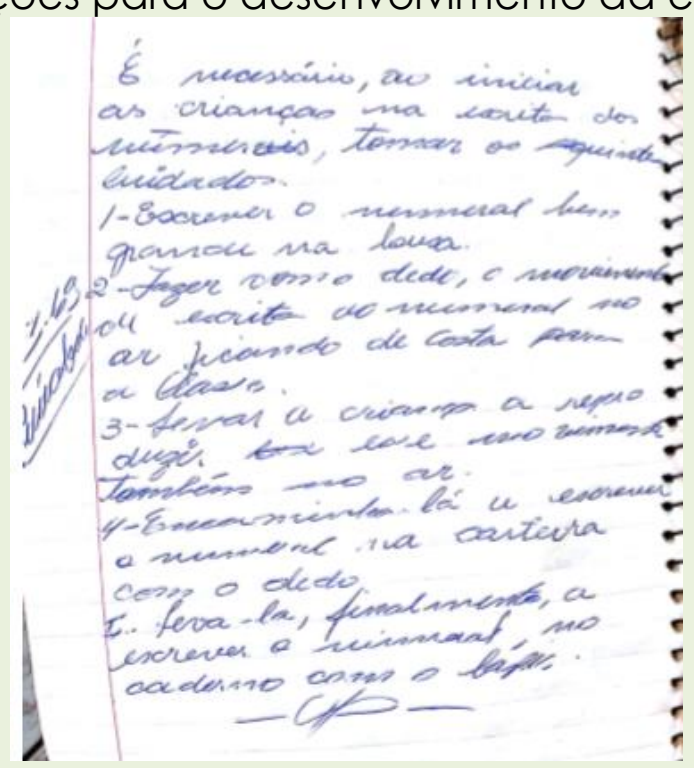

Fonte: Arquivo Pessoal da Professora Leiga. 
Algumas ações propostas previam $\circ$ desenvolvimento da coordenação motora e estão ligadas também aos estudos de Psicologia de Piaget. Evidenciamos assim, que as práticas formativas com influência do MMM, possuíam relações com da Psicologia como já abordado por Valente (2012).

O Caderno de Práticas do ensino da Matemática tinha como objetivo fazer com que a futura docente experienciasse como ensinar a Teoria dos Conjuntos. Como podemos ver, nas figuras:

FIGURA 3: Os conjuntos

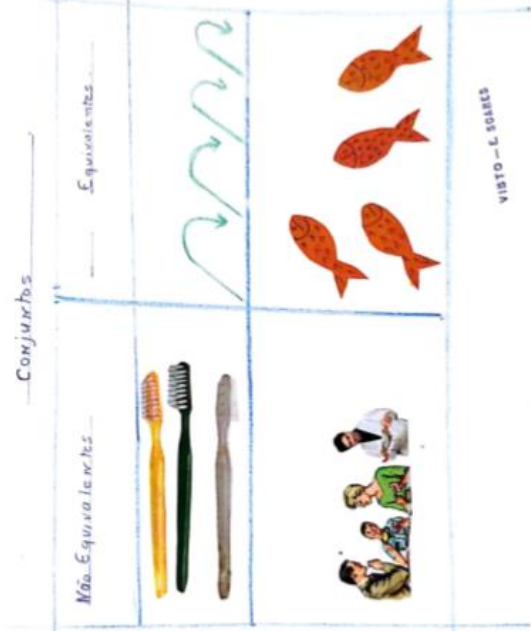

Fonte: Arquivo Pessoal da Professora Leiga.
FIGURA 4: Limite do conjunto

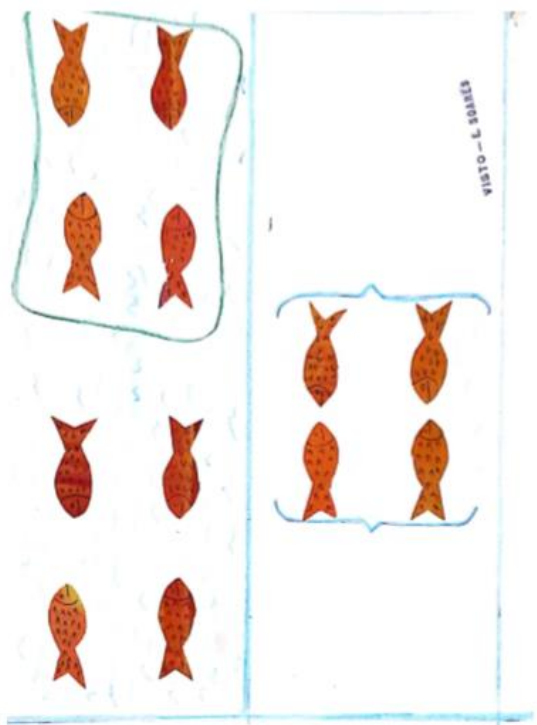

A figura 3 representa neste tipo de atividade prática passada a professora leiga, a identificação e a comparação dos conjuntos, no que se refere à equivalência e a não equivalência. A figura 4 permitia que a professora identificasse um conjunto menor dentro de um conjunto maior. Contudo, percebe-se que essas atividades eram desenvolvidas de uma forma bem prática e até mesmo técnica, no sentido do como fazer, por meio de ilustrações, que futuramente a docente poderia realizar em suas aulas na escola primária.

Figura 5: Quantidades

Figura 6: Percepção de conjuntos 

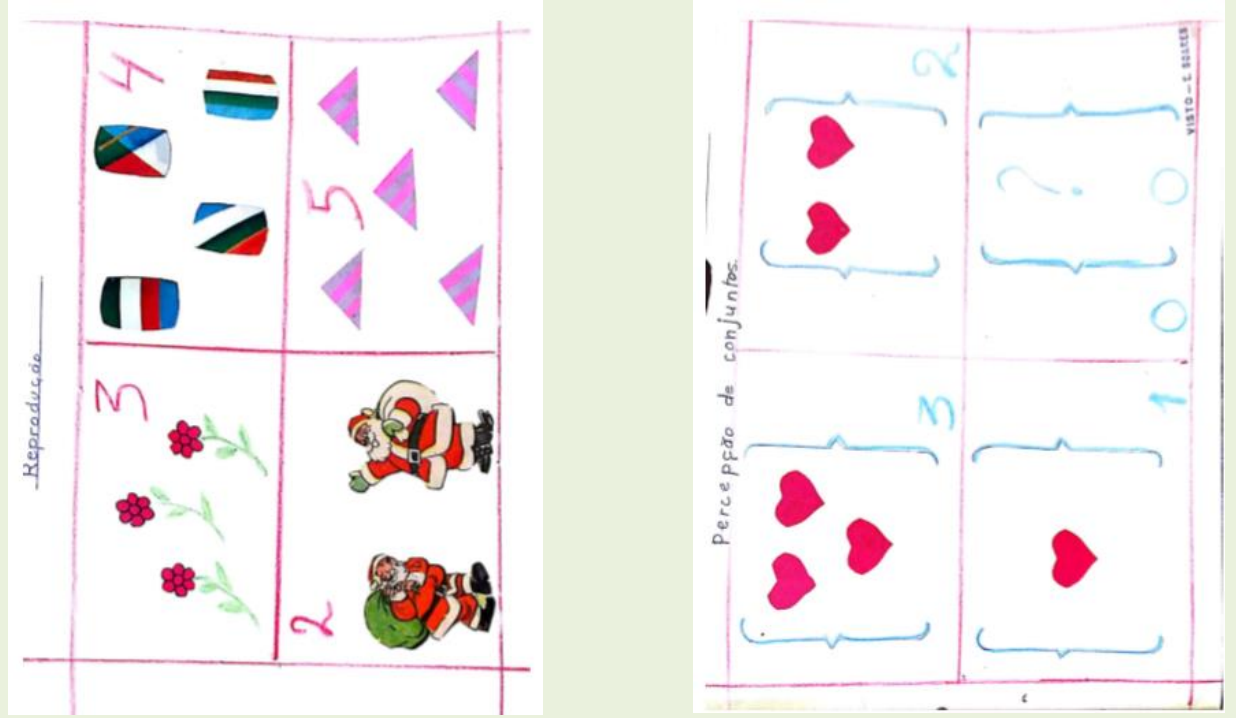

Fonte: Arquivo Pessoal da Professora Leiga

As figuras 5 e 6 também trabalham a perspectiva da Teoria dos Conjuntos, no entanto, por meio de atividades práticas que reproduziam as quantidades. Percebe-se assim, a presença de desenhos e recortes bem coloridos para o ensino desta prática, que também poderia ser aplicado pela professora futuramente na escola.

Figura 7: Agrupamentos

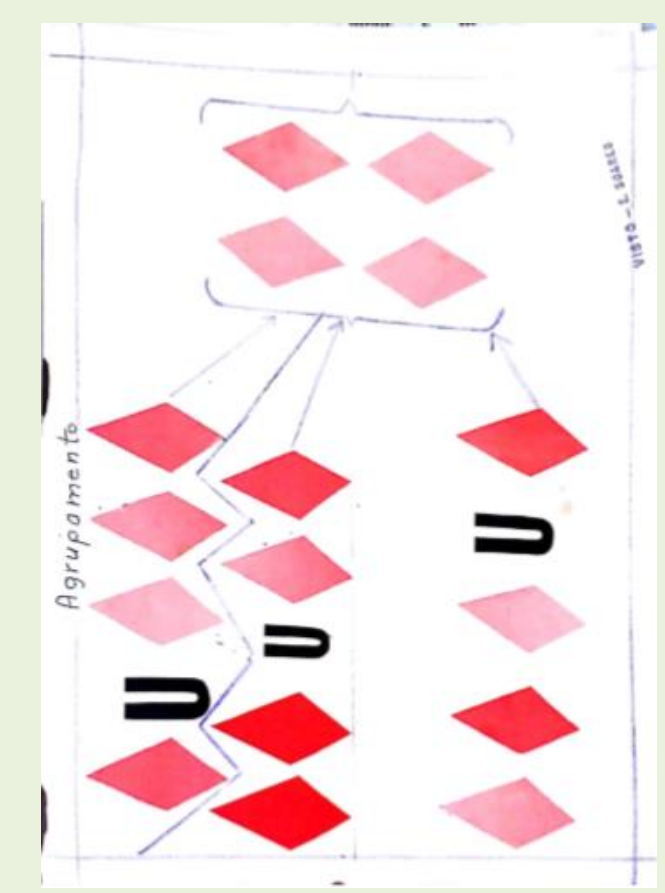

Fonte: Arquivo Pessoal da Professora Leiga. 
A figura 7 do mesmo modo que, as figuras anteriores estão relacionadas ao ensino do conteúdo da Teoria dos Conjuntos. Também com 0 uso de recortes e muitas cores representava de forma prática e técnica os agrupamentos, mostrando que para a construção do entendimento do conjunto de quatro elementos precisava entender que um conjunto unido a outro conjunto de três elementos formava um conjunto de quatro elementos. Certamente, todas as atividades que poderiam ser utilizadas pela professora futuramente na sala de aula do ensino primário.

Essas atividades práticas desenvolvidas no caderno permitem entender como a formação desses professores primários sofria influência do MMM, conforme estudos de Brasil (1998), Wielewski (2008), Valente (2012). Entretanto, pode-se perceber que a parte prática das atividades não se relaciona e nem mesmo fazia associações ao cotidiano. Evidenciamos assim, que a formação do professor primário leigo no ensino de Matemática centrava-se no estudo do como fazer, sugerindo atividades passo a passo para o ensino, correspondendo bem, aos propósitos da formação do Centro de Treinamento do Magistério de Cuiabá, que buscava proporcionar uma formação tecnicista aos professores, conforme discutido anteriormente neste texto.

Em linhas gerais, pode-se dizer que esses Cadernos permitiram compreender e refletir como ocorria a formação de professores primários leigos em um Curso de Regentes do Ensino Primário, no que diz respeito a sua formação no ensino da Matemática. Assim, os cadernos escolares enquanto fontes privilegiadas para a pesquisa constituem por meio dos conteúdos que temos acesso pistas, indícios do ocorrido em sala de aula, conforme apontam Santos (2008), Oliveira (2008), Frago(2008) e Faria (1998).

\section{CONSIDERAÇÕES FINAIS}

Ao longo deste artigo que busca analisar a história da formação dos professores que ensinavam Matemática, de $1^{a}$ a $4^{a}$ séries, em escolas situadas no meio rural no Sul de Mato Grosso, no município de Dourados, na década de 1960, focalizando especificamente a formação de uma 
professora leiga que fez o Curso de Regentes no Centro de Treinamento do Magistério de Cuiabá, no ano de 1969, foi possível identificar que esses professores recebiam uma formação rápida, devido a própria necessidade do estado de Mato Grosso, em diplomar o seu grande contigente de docentes leigos. Assim, pode-se notar que essa formação era dada no passo a passo, no sentido do como fazer e de forma bem tecnicista. Afinal, esses eram os propósitos dos cursos postos em funcionamento pelo Centro de Treinamento do Magistério de Cuiabá, que atendia com isso, uma proposta em âmbito federal, no que diz respeito à formação do professor leigo.

Contudo, nessa pesquisa que buscou focalizar a questão da história da formação desse professor primário leigo, no que diz respeito ao ensino de Matemática, constatou-se que em Mato Grosso, o Movimento da Matemática Moderna influenciava a formação de professores desde a década de 1960, conforme ficou evidenciado na formação da docente leiga, que fez o Curso de Regentes do Ensino Primário, em 1969, no Centro de Treinamento do Magistério de Cuiabá. Isso se pode observar, principalmente, no Caderno de Didática da Aritmética, uma vez que, a abordagem dessa própria disciplina da formação desses professores, surgiu com esse Movimento da Matemática Moderna.

Ainda foi possível verificar que um bom exemplo, dessa influência na formação de professores primários leigos na década de 1960, em Mato Grosso, esteve representada neste artigo, na análise sobre o Caderno de Didática da Matemática, em que aparecem registradas sugestões de atividades sobre a Teoria dos Conjuntos, pois essa Teoria somente surgiu após o Movimento da Matemática Moderna.

Assim, ao finalizar este artigo pode-se dizer que o Movimento da Matemática Moderna em Mato Grosso, influenciou a história da formação dos professores primários leigos que ensinavam Matemática e frenquentaram os cursos oferecidos pelo Centro de Treinamento do Magistério de Cuiabá. 


\section{REFERÊNCIAS}

BRASIL. Ministério da Educação e Cultura. Plano Trienal de Educação 19631965. Brasília: Departamento de Imprensa Nacional, 1963

BRASIL, Secretaria de Educação Fundamental. Parâmetros curriculares nacionais : matemática / Secretaria de Educação Fundamental. - Brasília: MEC/SEF, 1998.

FARIA, V. L. B. No caderno da criança o retrato da escola. 1998, 258 f. Dissertação (Mestrado em Educação) - FE/UFMG, Belo Horizonte: 1988.

FERREIRA, M. dos S. "O Centro de Treinamento do Magistério de Cuiabá e a profissionalização docente em Mato Grosso". Revista de Educação Pública. Cuiabá: UFMT, vol.19. núm. 30, pp.145-161, ja./abr.2010.

FRAGO, A. V. Os Cadernos escolares como fonte histórica: aspectos metodológicos e historiográficos. In: MIGNOT, A. C. . Cadernos a vista: Escola, Memória e Cultura escrita. Rio de Janeiro: edUERJ, 2008

FURTADO, A. C.; BICUDO, C. P.; ALENCAR, E. S. de. O Ensino de Matemática em ma Escola Rural no Sul de Mato Grosso- Brasil: Análise de um Caderno de Planejamento de Aulas (1989). Espaço Plural (Marechal Cândido Rondon. Online), v. 18, p. 94-122, 2017.

MARCÍlIO, H. História do Ensino em Mato Grosso. Cuiabá: Secretaria de Educação, Cultura e Saúde, 1963.

NÓVOA, A. (Coord.). Os professores e a sua formação. 2 ed. Lisboa: Dom Quixote, 1995.

PINHO, P. M. de INEP: Súmula das atividades desenvolvidas em 1963. Boletim Informativo CBPE. Brasil: Brasília, núm. 79, pp. 1-9, 1964.

OLIVEIRA, I. B. de. Aprendendo com os cadernos escolares: sujeitos, subjetividades e práticas sociais cotidianas na escola. In: MIGNOT, A. C. V. Cadernos a vista: Escola, Memória e Cultura escrita. Rio de Janeiro: edUERJ, 2008.

RODRIGUES. J. R. T. "Magistério Leigo Rural do Piauí: Concepções e Práticas". 1985. 268f. Dissertação Mestrado em Educação. Pontifícia Universidade Católica. São Paulo, 1985.

SANTOS, A. A. C. Aprendendo a usar cadernos: um caminho necessário para a inserção na cultura escolar. In: MIGNOT, A. C. V. Cadernos a vista: Escola, Memória e Cultura escrita. Rio de Janeiro: edUERJ, 2008.

VALENTE, W. O que é número? Produção, circulação e apropriação da Matemática Moderna para crianças. Bolema, Rio Claro (SP), v. 26, n. 44, p. 1417-1441, dez. 2012 
WIELEWSKI, G. D. O Movimento da Matemática Moderna e a formação de grupos de professores de Matemática no Brasil. In: ProfMat2008, 2008, ElvasPortugal. ProfMat2008 Actas. Lisboa-Portugal: Associação de Professores de Matemática, 2008.

Recebido em: 28 de setembro de 2018 Aprovado em: 15 de janeiro de 2019 